\title{
Evaluation of the impact of genetic polymorphisms in glutathione-related genes on the association between methylmercury or $n-3$ polyunsaturated long chain fatty acids and risk of myocardial infarction: a case-control study
}

Karin S Engström', Maria Wennberg 2,3, Ulf Strömberg ${ }^{1}$, Ingvar A Bergdahl', Göran Hallmans ${ }^{3}$, Jan-Håkan Jansson ${ }^{2,3}$, Thomas Lundh', Margareta Norberg ${ }^{3}$, Gerda Rentschler ${ }^{1}$, Bengt Vessby ${ }^{4}$, Staffan Skerfving ${ }^{1}$ and Karin Broberg ${ }^{1 *}$

\begin{abstract}
Background: The n-3 polyunsaturated fatty acids eicosapentaenoic acid and docosahexaenoic acid, which are present in fish, are protective against myocardial infarction. However, fish also contains methylmercury, which influences the risk of myocardial infarction, possibly by generating oxidative stress. Methylmercury is metabolized by conjugation to glutathione, which facilitates elimination. Glutathione is also an antioxidant. Individuals with certain polymorphisms in glutathione-related genes may tolerate higher exposures to methylmercury, due to faster metabolism and elimination and/or better glutathione-associated antioxidative capacity. They would thus benefit more from the protective agents in fish, such as eicosapentaenoic+docosahexaenoic acid and selenium. The objective for this study was to elucidate whether genetic polymorphisms in glutathione-related genes modify the association between eicosapentaenoic+docosahexaenoic acid or methylmercury and risk of first ever myocardial infarction.
\end{abstract}

Methods: Polymorphisms in glutathione-synthesizing (glutamyl-cysteine ligase catalytic subunit, GCLC and glutamyl-cysteine ligase modifier subunit, GCLM) or glutathione-conjugating (glutathione S-transferase P, GSTP1) genes were genotyped in 1027 individuals from northern Sweden (458 cases of first-ever myocardial infarction and 569 matched controls). The impact of these polymorphisms on the association between erythrocyte-mercury (proxy for methylmercury) and risk of myocardial infarction, as well as between plasma eicosapentaenoic +docosahexaenoic acid and risk of myocardial infarction, was evaluated by conditional logistic regression. The effect of erythrocyte-selenium on risk of myocardial infarction was also taken into consideration.

Results: There were no strong genetic modifying effects on the association between plasma eicosapentaenoic +docosahexaenoic acid or erythrocyte-mercury and risk of myocardial infarction risk. When eicosapentaenoic +docosahexaenoic acid or erythrocyte-mercury were divided into tertiles, individuals with GCLM-588 Tा genotype displayed a lower risk relative to the CC genotype in all but one tertile; in most tertiles the odds ratio was around 0.5 for $\pi$. However, there were few $\pi$ carriers and the results were not statistically significant. The results were similar when taking plasma eicosapentaenoic+docosahexaenoic acid, erythrocyte-selenium and erythrocyte-mercury into account simultaneously.

Conclusions: No statistically significant genetic modifying effects were seen for the association between plasma eicosapentaenoic+docosahexaenoic acid or erythrocyte-mercury and risk of myocardial infarction. Still, our results

\footnotetext{
* Correspondence: karin.broberg@med.lu.se

'Division of Occupational and Environmental Medicine, Lund University,

Lund, Sweden

Full list of author information is available at the end of the article
} 
indicate that the relatively rare GCLM-588 $\pi$ genotype may have an impact, but a larger study is necessary for confirmation.

Keywords: Methylmercury myocardial infarction, polymorphisms, glutathione, n-3 polyunsaturated long chain fatty acids

\section{Background}

The toxic compound methylmercury ( $\mathrm{MeHg}$ ) from fish may increase the risk of myocardial infarction (MI), possibly due to induction of oxidative stress, a risk factor for MI. High mercury $(\mathrm{Hg})$ levels in hair (proxy for $\mathrm{MeHg}$ retention) [1,2] and toenails (proxy for $\mathrm{MeHg}$ ) [3] have been associated with an increased risk of MI. However, high $\mathrm{Hg}$ levels in erythrocytes (Ery-Hg; proxy for $\mathrm{MeHg}$ ) have been associated with a decreased risk of MI in some studies [4,5]. This discrepancy between studies and populations may partly be explained by different $\mathrm{MeHg}$ exposure levels in different studies. However, genetic differences between individuals and populations may explain some of these discrepancies; some individuals may have a genetic setup giving a more beneficial $\mathrm{MeHg}$ metabolism, resulting in a faster MeHg-elimination [6,7] and/or differences in capacity to detoxify reactive oxygen species induced by $\mathrm{MeHg}$. Individuals with a more beneficial MeHg metabolism and/or a better capacity to detoxify reactive oxygen species may be able to tolerate higher exposures to MeHg. Subsequently, they would benefit more from protective agents in fish, the major source of $\mathrm{MeHg}$ exposure. Protective agents include the n-3 polyunsaturated long chain fatty acids eicosapentaenoic acid (EPA) and docosahexaenoic acid (DHA) (their sum referred to as EPA+DHA), which has antiatherogenic, antithrombotic and antiarrhythmic properties [8,9], as well as selenium (Se), which may protect against MI due to its presence in the antioxidant enzyme glutathione peroxidase.

$\mathrm{MeHg}$ is eliminated in the bile as a glutathione (GSH) conjugate $[10,11]$. The rate-limiting enzyme for GSH synthesis is glutamyl-cysteine ligase (GCL), which is composed of a catalytic subunit (GCLC [Unigene: Hs.654465] [12]) and a modifier subunit (GCLM [Unigene: Hs.315562]). The glutathione $S$-transferases (GSTs), which conjugate GSH to a wide variety of electrophilic compounds $[13,14]$, may also affect the metabolism of MeHg. Polymorphisms with a functional impact in genes coding for GSH-synthesizing (GCLC, GCLM) or GSH-conjugating (GSTs) enzymes may thus influence the elimination capacity. Polymorphisms affecting GSH production (lower promoter activity for the variant alleles) have been found in both subunits; a $C \rightarrow T$ nucleotide substitution at position -129 in GCLC (GCLC-129) $[15,16]$ and a $C \rightarrow T$ nucleotide substitution at position -588 in GCLM [17]. Glutathione-S- transferase pi (GSTP1 [Unigene [12]: Hs.523836]) exhibits a number of genetic polymorphisms, of which the Ile105Val and Ala114Val amino acid substitutions both have been associated with differences in enzyme activity and substrate preferences [18-20]. Furthermore, GSH is an antioxidative agent, and polymorphisms in GCLC, GCLM and GSTP1 may thus modify the MeHg-induced oxidative damage.

In our previous study [7], we evaluated the genetic impact on $\mathrm{MeHg}$ metabolism. This study did not include any MI cases and consisted of different study subjects than the present study. We found that carriers of the variant alleles for the GSTP1 polymorphisms GSTP1-105 or GSTP1-114 had lower levels of Ery-Hg at high plasma EPA+DHA, compared with individuals with no variant alleles, indicating a faster elimination of $\mathrm{MeHg}$ for variant-allele carriers. Also, TT homozygotes for the GCLM-588 polymorphism demonstrated higher Ery-Hg than the other GCLM-588 genotypes. Polymorphisms in GCLC, GCLM and/or GSTP1 have been associated with body burden of $\mathrm{Hg}$ in other studies $[6,21,22]$.

The present study is an extension of a study by Wennberg et al [5], which evaluated the impact of PEPA+DHA and Ery-Hg on MI risk in this study population. The study by Wennberg et al. found that Ery-Hg was statistically significantly associated with a decreased risk of MI, while EPA+DHA in plasma indicated a decreased risk of MI (not statistically significant). The aim of the present study was to elucidate whether polymorphisms in genes potentially involved in $\mathrm{MeHg}$ metabolism and/or antioxidant defense can modify the association between EPA+DHA or Ery-Hg and MI risk. The effect of erythrocyte-Se (Ery-Se) on MI risk was also considered.

\section{Methods}

\section{Study population}

The study population is part of an individually matched case-control study nested within three prospective health surveillance cohorts in Västerbotten, Northern Sweden: the Västerbotten Intervention Program (VIP), the WHO's Multinational Monitoring of Trends and Determinants in Cardiovascular Disease (MONICA) Study in northern Sweden, and the Mammography Screening Project (MSP). Both VIP and MONICA are health examination programs for CVD and diabetes. 
Table 1 Descriptive data of the study population

\begin{tabular}{|c|c|c|c|c|c|c|c|c|}
\hline & \multicolumn{4}{|c|}{ Controls } & \multicolumn{4}{|c|}{ Cases } \\
\hline & $\mathrm{N}$ & Mean & SD & Range & $N$ & Mean & SD & Range \\
\hline Ery-Hg $(\mu \mathrm{g} / \mathrm{l})$ & 569 & 4.9 & 5.1 & $\begin{array}{c}0.19- \\
81\end{array}$ & 458 & 4.5 & 5.7 & $\begin{array}{c}0.010- \\
87\end{array}$ \\
\hline P-EPA+DHA (\%) & 508 & 6.2 & 1.6 & $2.8-14$ & 408 & 6 & 1.5 & $3.2-15$ \\
\hline Ery-Se $(\mu \mathrm{g} / \mathrm{l})$ & 568 & 130 & 37 & $75-710$ & 458 & 130 & 22 & $72-210$ \\
\hline ApoB/apoA1 & 567 & 0.8 & 0.26 & $\begin{array}{c}0.14- \\
2.1 \\
\end{array}$ & 457 & 0.95 & 0.25 & $0.21-2.1$ \\
\hline BMI $\left(\mathrm{kg} / \mathrm{m}^{2}\right)$ & 435 & 26 & 4 & $18-49$ & 378 & 27 & 4 & $18-57$ \\
\hline Smokers & 555 & $19 \%$ & & & 433 & $42 \%$ & & \\
\hline $\begin{array}{l}\text { Fish (meals/ } \\
\text { week) }\end{array}$ & 427 & 1.3 & 0.79 & $0.0-5.5$ & 354 & 1.2 & 0.94 & $0.0-8.0$ \\
\hline -lean fish & 431 & 0.72 & 0.67 & $0.0-6.5$ & 365 & 0.68 & 0.58 & $0.0-4.0$ \\
\hline fat fish & 433 & 0.57 & 0.47 & $0.0-4.0$ & 361 & 0.58 & 0.58 & $0.0-4.0$ \\
\hline
\end{tabular}

Abbreviations: SD, standard deviation; Ery- $\mathrm{Hg}$, erythrocyte total mercury concentration; Ery-Se, erythrocyte selenium concentration.

The cohorts, sampling and other variables are described more thoroughly in Wennberg et al. [5]. Medical history and lifestyle information was obtained at baseline in 1987 - 1999 (Table 1). Venous blood was sampled and erythrocytes, serum and plasma were separated and stored in a biobank at $-80^{\circ} \mathrm{C}$. Controls were matched to the cases for first ever MI (one control for each male case and two for each female case) for sex, age $( \pm 2$ years), date of health survey ( \pm 4 months) and geographical region. Cases and controls were excluded if previous MI, stroke, or malignant disease could not be excluded according to the questionnaire or case records. Erythrocytes and DNA were available from 1027 individuals (458 cases and 569 controls); 42 cases and 56 controls were missing compared with Wennberg et al. [5], due to lack of samples for DNA extraction. Plasma was available from 916 individuals (408 cases and 508 controls). Data on smoking was missing for 39 individuals, and data on apolipoprotein B/A1 ratio (ApoB/ApoA1) was missing for 3 individuals. Smoking habits were classified into "daily smoking" or "nonsmoking" (including previous smokers and occasional smokers). The study was approved by the Regional Ethics Committee of Umeå University. Participants gave written informed consent prior to the study.

\section{Measurement of Ery-Hg, Ery-Se and P-EPA+DHA}

The determination of Ery-Hg was made in acid-digested samples using cold vapor atomic fluorescence spectrometry $[5,7,23]$. Plasma fatty acids were separated by gasliquid chromatography after separation of the lipids by thin layer chromatography and transmethylation [24]. Plasma EPA+DHA (P-EPA+DHA) was calculated as the percent in plasma phospholipids $[4,25]$. APOA1 and APOB were measured by immunoturbidimetry, while
Ery-Se was measured by inductively coupled plasma mass spectrometry (ICP-MS; Thermo $\times 7$; Thermo Elemental, Winsford, United Kingdom).

More detailed information, such as limit of detection, coefficients of variance, and reference material are thoroughly described in Wennberg et al. [5].

\section{Genotype analyses}

The Taqman allelic discrimination assay (ABI 7000, Applied Biosystems, Foster City, CA, USA) was performed to analyze all four single nucleotide polymorphisms (SNPs) separately; GCLC-129, GCLM-588, GSTP1105 and GSTP1-114 [6,7]. There was a total agreement between the original and repeat genotyping runs in all of the four SNPs analyzed. Genotype frequencies as well as the ID numbers (rs numbers [26]) for the polymorphisms are presented in Table 2.

\section{Statistical analysis}

Hardy-Weinberg equilibrium was tested for the controls using the conventional Chi-square test. Because the effects of P-EPA+DHA, Ery-Se and Ery-Hg on MI risk were in the same direction for men and women [5], both genders were combined in the multivariate analyses. Due to a lot of missing data for some of the background variables (especially for females), we only considered adjustments for age, smoking, BMI, year of sampling, and $A$ poB/ApoA1. In total, we employed four genetic markers (GCLC-129, GCLM-588, GSTP1-105 and GSTP1-114). Effects of dual-polymorphisms for the GSTP1 gene (GSTP1-105 and GSTP1-114) were also analyzed, where genotype was categorized as the total number of variant alleles for both polymorphisms. Individuals with two or more variant alleles were pooled

Table 2 Genotype frequencies for GCLC-129, GCLM-588, GSTP1-105 and GSTP1-114

\begin{tabular}{llll}
\hline Gene & Polymorphism & Genotype & Frequency (\%) \\
\hline GCLC & $-129 C / T$ & CC & 86 \\
\hline rs17883901 & CT & 13 \\
\hline & $\pi$ & 0.5 \\
\hline GCLM & $-588 C / T$ & $C C$ & 75 \\
\hline rs41303970 & CT & 22 \\
\hline GSTP1 & Ile105Val & Ile/lle & 51 \\
\hline rS1695 & & IleNal & 40 \\
\hline & ValNal & 8.8 \\
\hline GSTP1 & Ala114Val & Ala/Ala & 82 \\
\hline rS1138272 & AlaNal & 17 \\
\hline & ValNal & 1.4 \\
\hline
\end{tabular}

Abbreviations: GCLC, glutamyl-cysteine ligase catalytic subunit; GCLM, glutamylcysteine ligase modifier subunit; GSTP1, glutathione-S-transferase Pi 1. 


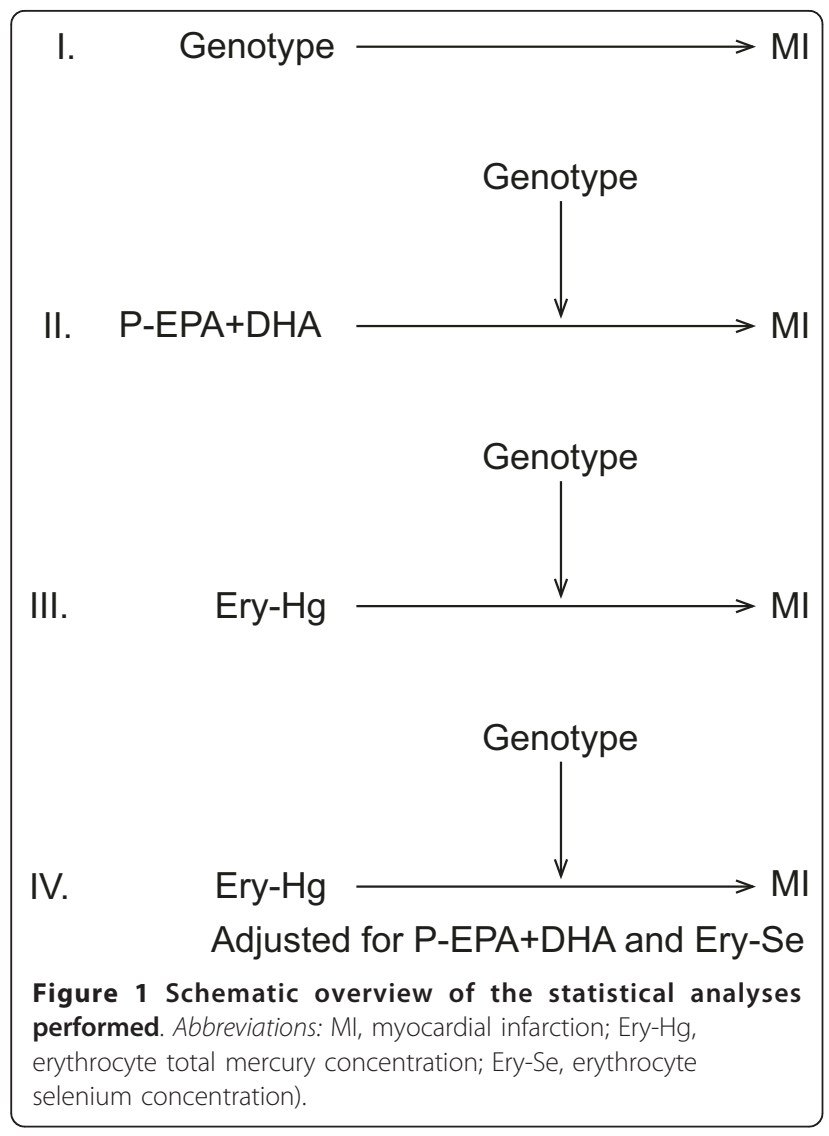

into one group. The genotypes were used as categorical variables in all analyses. Since this study is an extension of the study by Wennberg et al [5], P-EPA+DHA and Ery-Hg were evaluated in a similar fashion - divided into tertiles - as in Wennberg et al [5].

A schematic overview of the statistical analyses are shown in Figure 1. For all analyses, a univariate conditional logistic regression model (unadjusted model), based on the matched case-control sets was performed, as well as a multivariate logistic regression model (adjusted model), including covariates that had a p-value $<0.05$.

Firstly, we evaluated whether genotype in itself had any effect on MI risk (I in Figure 1). For each polymorphism, the group with the most common homozygous genotype was used as reference. For the GSTP1105 and GSTP1-114 combination, the group with individuals with 0 variant alleles was used as reference.

Secondly, we evaluated whether the association between P-EPA+DHA and MI risk was modified by genotype due to its potential impact on $\mathrm{MeHg}$ metabolism (II in Figure 1). Genetic factors may have an impact on $\mathrm{MeHg}$ metabolism, resulting in an individual variation regarding retention and elimination of $\mathrm{MeHg}$ at similar exposure levels. Differences in retention/elimination lead to differences in the amount of $\mathrm{MeHg}$ that has the opportunity to target vulnerable organs and cause toxic effects that may increase the risk of MI. In order to evaluate this, P-EPA+DHA can be used as a proxy for intake of $\mathrm{MeHg}$, since P-EPA+DHA correlates with the body burden of MeHg. P-EPA+DHA was stratified into three groups, according to tertiles in the controls (0$5.39,5.40-6.68$, and 6.69-15\%, respectively). A univariate and a multivariate conditional logistic regression model were run for each stratum. The group consisting of the most common homozygotes at the lowest P-EPA+DHA tertile was used as reference.

Thirdly, we evaluated whether the association between Ery-Hg and MI risk was modified by genotype, due to its potential role in protection against oxidative stress (III in Figure 1). Ery-Hg was stratified according to tertiles in the controls $(0-2.81,2.82-4.79$, and 4.83-87 $\mu \mathrm{g} / \mathrm{l}$, respectively). The tertile boundaries differed somewhat from Wennberg et al. [5], due to a different number of individuals. A univariate and multivariate conditional logistic regression model were run for each stratum. The group consisting of the most common homozygotes at the lowest Ery-Hg tertile was used as reference.

Fourthly, we evaluated whether the effect of Ery-Hg on MI risk was modified by genotype (IV in Figure 1), when adjustments were done for P-EPA+DHA and ErySe.

Because of the low allelic frequencies and similar effects of some genotypes, the heterozygotes and homozygous variant genotypes for the same gene were pooled in all analyses for GCLC-129 and GSTP1-114.

All statistical analyses were performed using the software SPSS (version 15; SPSS, Chicago, IL, USA). All tests were two-sided and $\mathrm{p} \leq 0.05$ was considered statistically significant.

\section{Results}

When genotype was not taken into account, P-EPA + DHA indicated a decreasing MI risk $(\mathrm{p}=0.15)$, while Ery-Hg was statistically significantly associated with decreasing MI risk ( $\mathrm{p}=0.014$ ) (Wald test for univariate analyses for the trichotomized biomarkers).

There were significant effects on MI risk by smoking (OR 3.2, 95\% CI 2.4, 4.5) and ApoB/ApoA1 (OR 12.7, $95 \%$ CI $6.7,24)$ and these two variables were thus included in the multivariate analyses.

All polymorphisms were in Hardy-Weinberg equilibrium (analyzed for controls only) except for GCLM$588(\mathrm{p}=0.030)$.

When evaluating the effect of genotype alone on MI risk (I in Figure 1), no significant results were seen. For example, the adjusted odds ratio (OR) for the GCLM588 TT genotype (GCLM-588 CC was used as reference) was 0.60 (95\% CI $0.24,1.5)$. 
There were no statistically significant genetic modifying effect of the associations between P-EPA+DHA or Ery- $\mathrm{Hg}$ and MI risk (Figures 2 and 3). The variant homozygotes $(T T)$ for the GCLM-588 polymorphism had a lower MI risk relative to wildtype homozygotes $(C C)$ in all P-EPA+DHA and Ery-Hg tertiles (Figures 2, graph $\mathrm{C}$ and 3, graph $\mathrm{C}$ ). The ORs for $T T$ were around 0.5 in most tertiles. However, this was not statistically significant and it was based on few individuals with the $T T$ genotype. Among the controls, the GCLM TT carriers demonstrated a mean Ery- $\mathrm{Hg}$ level of $5.4 \mu \mathrm{g} / \mathrm{l}$ among the controls compared to $4.9 \mu \mathrm{g} / \mathrm{l}$ among the $G C L M C C+C T$ carriers ( $\mathrm{p}$-value $=0.65$, ANOVA).

For GSTP1 (combination of GSTP1-105 and GSTP1114), carriers of two or more variant alleles showed the lowest risk in all Ery-Hg tertiles (Figure 3, graph F). However, the differences were not statistically significant.

All analyses gave similar genetic modifying effects on the association between Ery- $\mathrm{Hg}$ and MI risk when

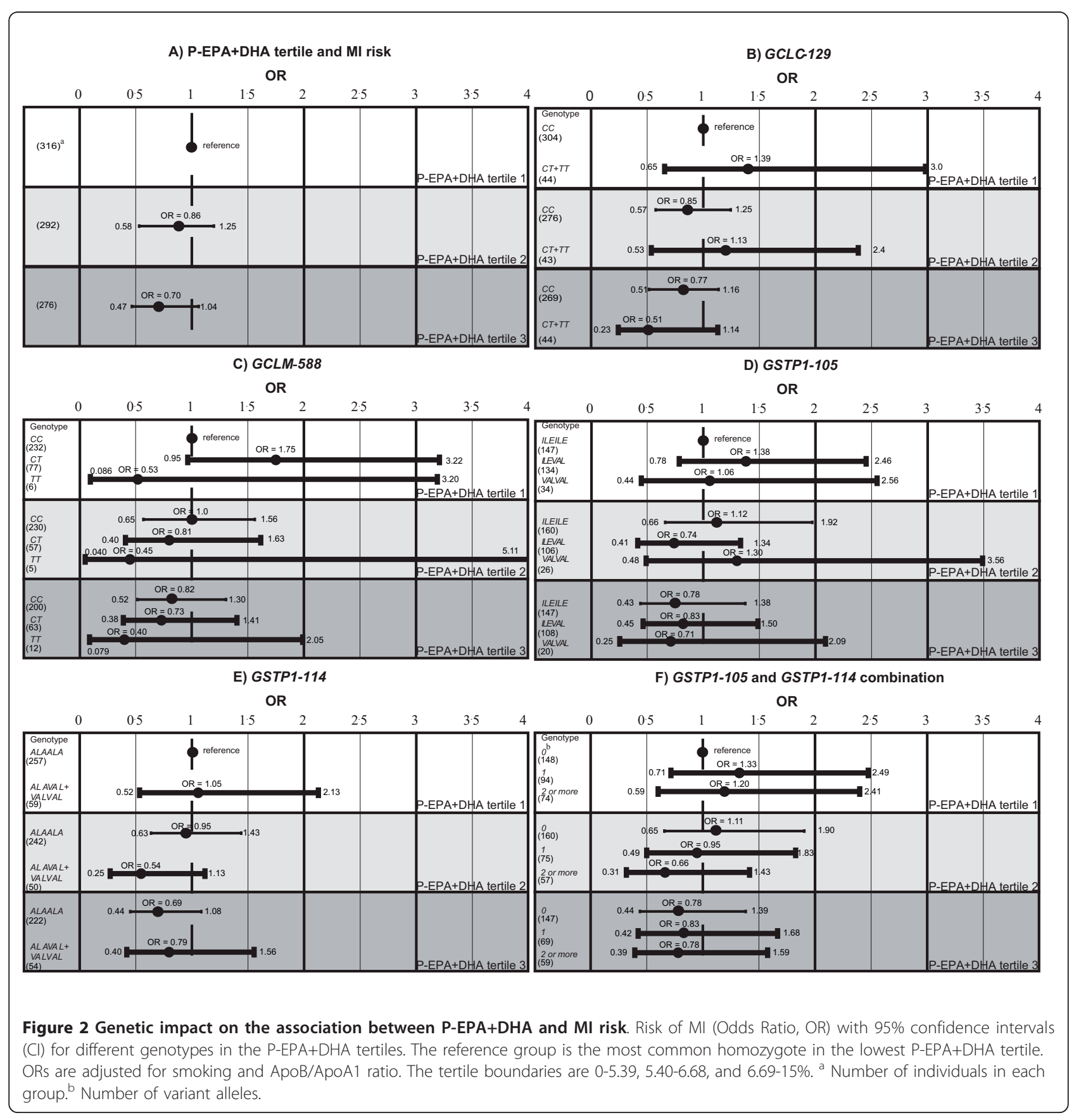




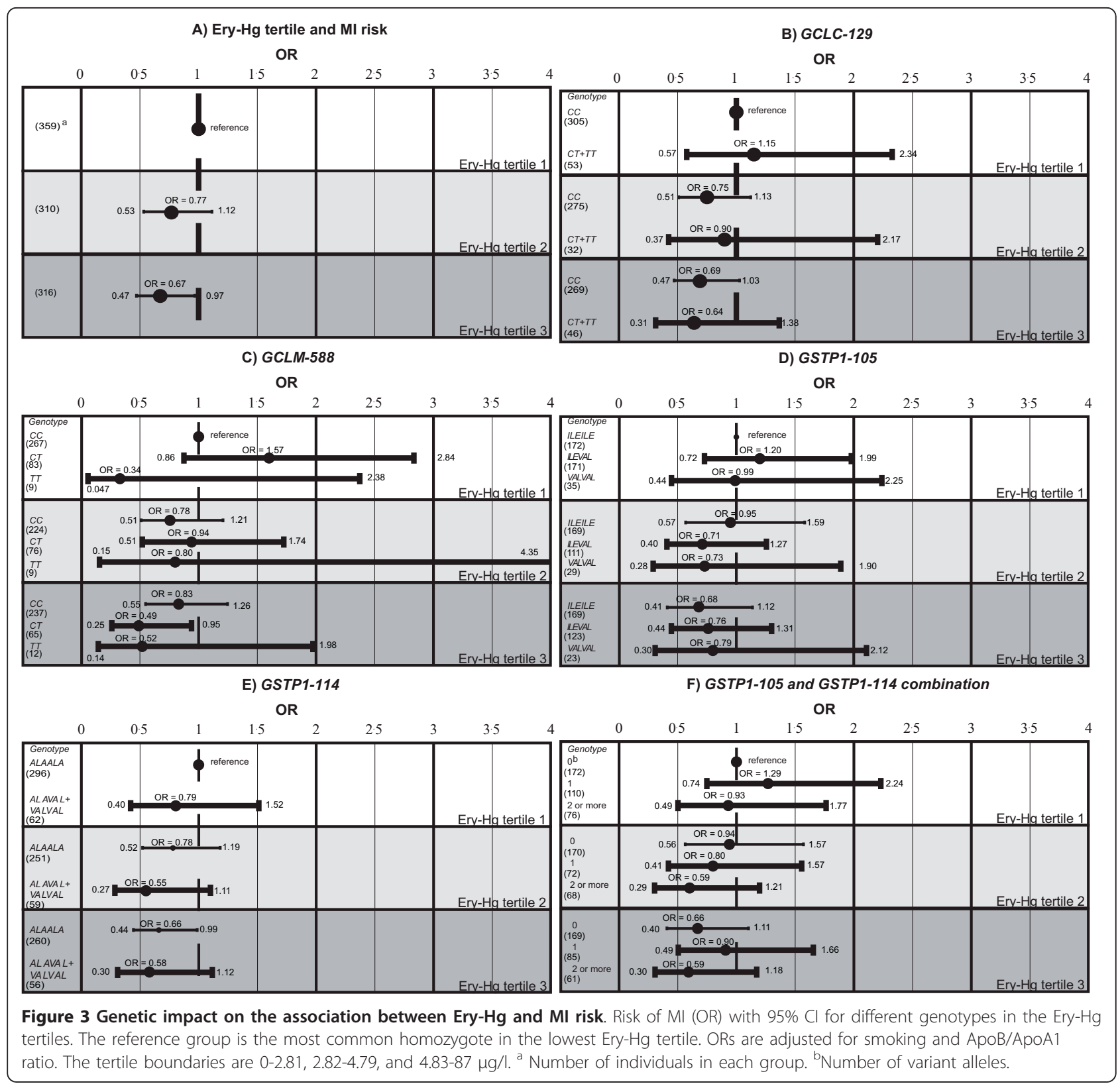

adjustments for P-EPA+DHA and Ery-Se were done compared with when no adjustments for P-EPA+DHA and Ery-Se were done (data not given here).

\section{Discussion}

Similar patterns as in Wennberg et al. [5] were seen regarding the associations between Ery- $\mathrm{Hg}$ and P-EPA +DHA, respectively, and MI risk. This is not surprising, since the study populations are, largely, the same in both studies. It is also in accordance with a previous, smaller study in the same region [4]. The protective effect of P-EPA+DHA is in concordance with numerous other studies. The association between high Ery-Hg and low MI risk is most likely because Ery-Hg is a marker of fish intake.

We found that the polymorphisms studied had no effect on MI risk by themselves. When P-EPA+DHA or/ and Ery-Hg was taken into account, the GCLM-588 TT genotype had a lower risk relative to the $C C$ genotype in all P-EPA+DHA or Ery-Hg tertiles except for one (intermediate tertile for Ery-Hg) (ORs generally around 0.5), but these findings were not statistically significant. The lack of statistically significant results in this study may be due to a small number of individuals for some genotypes, in particular GCLM-588 TT, yielding a too low power to detect statistically significant effects. The effect 
estimates (ORs) for GCLM-588 TT were strongly deviant from the $C T$ genotype, which prevented us from pooling these two genotypes. In our previous study, the GCLM-588 TT genotype demonstrated the highest levels of Ery-Hg [7]. The GCLM-588 TT genotype had the highest levels of Ery-Hg also among the controls in this study, although this was not significant. GCLM-588 TT carriers displayed the lowest risk of MI in each P-EPA +DHA tertile in this study. However, it is important to note that this interpretation is based on few individuals and needs to be confirmed.

The GCLM-588 was in Hardy-Weinberg disequilibrium. The allele frequencies reported here were similar to another study, analyzing Danish and Swiss populations, where Hardy-Weinberg equilibrium was reported [27]. The preceding gene-environment studies for $\mathrm{MeHg}$ with individuals from the same geographical area $[6,7]$ also showed linkage disequilibrium, while we observed equilibrium in other studies by our group, employing the same methods, but in other populations [21,28]. Therefore, the linkage disequilibrium may be population-specific.

To our knowledge, no other studies have assessed gene-environment interactions (for any gene) on the association between $\mathrm{MeHg}$ or $\mathrm{n}-3$ polyunsaturated fatty acids and MI risk. There may, however, also be other genetic traits that can influence these associations, e.g. polymorphisms in other GSH-related genes, such as glutathione peroxidase (GPX1), glutaredoxin (GLRX), gamma-glutamyl transferase 1 (GGT1), or in any of the other GSTs. It is also possible that thioredoxin (TXN) and TXN-related genes affect the metabolism of MeHg [29]. In addition to the genes we studied, there may be an influence of other genes involved in oxidative stress, such as catalase $(C A T)$, paroxonases (PONs) and superoxide dismutase ( $S O D$ ).

A number of studies have investigated the genetic impact on MI risk. Some included genes potentially involved in protection against oxidative stress: the GCLM-588 T-allele has been associated with a higher risk of MI (non-lethal cases [17]). The T-allele showed a lower promoter activity in response to oxidants, and the increase of mRNA expression in response to oxidants was significantly lower among $C T$ subjects, compared to $C C$ subjects. The variant allele of GCLC-129 has also been associated with MI [16]. However, none of these findings was confirmed in our study.

\section{Conclusions}

There was no statistically significant genetic modifying impact on the association between P-EPA+DHA or Ery$\mathrm{Hg}$ and MI risk. Still, our results indicate that the relatively rare GCLM-588 TT genotype may have an impact, but a larger study is necessary for testing this hypothesis.

\section{List of abbreviations}

ApoB/A1: Apolipoprotein B/A1 ratio; BMl: Body mass index; $\mathrm{Cl}$ : Confidence interval; DHA: Docosahexaenoic acid; EPA: Eicosapentaenoic acid; Ery-Hg: Erythrocyte total mercury concentration; Ery-Se: Erythrocyte selenium concentration; GCL: Glutamyl-cysteine ligase; GCLC: Glutamyl-cysteine ligase catalytic subunit; GCLM: Glutamyl-cysteine ligase modifier subunit; GSH: Glutathione; GST: Glutathione-S-transferase; GSTP1: Glutathione-S-transferase Pi 1; Hg: Mercury; MeHg: Methylmercury; MI: Myocardial infarction; OR: Odds ratio; SD: Standard deviation; Se: Selenium; SNP: Single nucleotide polymorphism.

\section{Acknowledgements}

This research was supported by grants from the European Union within the Sixth Framework Programme for RTD ("PHIME" contract no FOOD-CT-2006016253. It reflects only the author's views. The Community is not liable for any use that may be made of the information contained therein), the Medical Faculty at Lund University, the County Councils of Southern Sweden, Västerbotten County Council, the Foundation of Medical Research in Skellefteå and the Swedish Council for Working Life and Social Research (METALUND). The authors declare they have no financial interest.

\section{Author details}

'Division of Occupational and Environmental Medicine, Lund University, Lund, Sweden. 'Department of Medicine, Skellefteå Hospital, Skellefteå, Sweden. ${ }^{3}$ Department of Public Health and Clinical Medicine, Umeå University, Umeå, Sweden. ${ }^{4}$ Department of Public Health and Caring Sciences, Uppsala University, Uppsala, Sweden.

\section{Authors' contributions}

KSE. contributed to data preparation, designed and carried out the data analyses, participated in interpretation of data, drafting and finalizing of the manuscript. MW contributed to data preparation, participated in interpretation of data, drafting and finalizing of the manuscript. US was advisor for the statistical analyses, contributed to interpretation of data, drafting and finalizing of the manuscript. IAB participated with input in the manuscript writing and analysis of the data. GH participated in the discussion initiating the study, collection and administration of data. TL carried out chemical analysis of Ery-Hg and Ery-Se. MN participated in the discussion initiating the study, collection and administration of data. GR performed genotyping analyses. BV carried out chemical analysis of fatty acids. SS participated in the discussion initiating the study, participated in data analyses, interpretation of data and drafting and finalizing of the manuscript. JHJ established the case-control study population. KB participated in the discussion initiating the study, participated in data analyses, interpretation of data and drafting and finalizing of the manuscript. All authors have read and approved the final manuscript.

\section{Competing interests}

The authors declare that they have no competing interests.

Received: 1 December 2010 Accepted: 19 April 2011

Published: 19 April 2011

\section{References}

1. Salonen JT, Seppanen K, Nyyssonen K, Korpela H, Kauhanen J, Kantola M, Tuomilehto J, Esterbauer H, Tatzber F, Salonen R: Intake of mercury from fish, lipid peroxidation, and the risk of myocardial infarction and coronary, cardiovascular, and any death in eastern Finnish men. Circulation 1995, 91:645-655.

2. Virtanen JK, Voutilainen S, Rissanen TH, Mursu J, Tuomainen TP, Korhonen MJ, Valkonen VP, Seppanen K, Laukkanen JA, Salonen JT: Mercury, fish oils, and risk of acute coronary events and cardiovascular disease, coronary heart disease, and all-cause mortality in men in eastern Finland. Arterioscler Thromb Vasc Biol 2005, 25:228-233.

3. Guallar E, Sanz-Gallardo MI, van't Veer P, Bode P, Aro A, Gomez-Aracena J, Kark JD, Riemersma RA, Martin-Moreno JM, Kok FJ: Mercury, fish oils, and the risk of myocardial infarction. N Engl J Med 2002, 347:1747-1754.

4. Hallgren CG, Hallmans G, Jansson JH, Marklund SL, Huhtasaari F, Schutz A, Stromberg U, Vessby B, Skerfving S: Markers of high fish intake are associated with decreased risk of a first myocardial infarction. $\mathrm{Br} J \mathrm{Nutr}$ 2001, 86:397-404. 
5. Wennberg M, Bergdahl IA, Hallmans G, Norberg M, Lundh T, Skerfving S Stromberg U, Vessby B, Jansson JH: Fish consumption and myocardial infarction: a second prospective biomarker study from northern Sweden. Am J Clin Nutr 2011, 93:27-36.

6. Custodio HM, Broberg K, Wennberg M, Jansson JH, Vessby B, Hallmans G, Stegmayr B, Skerfving S: Polymorphisms in glutathione-related genes affect methylmercury retention. Arch Environ Health 2004, 59:588-595.

7. Schlawicke Engstrom K, Stromberg U, Lundh T, Johansson I, Vessby B, Hallmans G, Skerfving S, Broberg K: Genetic variation in glutathionerelated genes and body burden of methylmercury. Environ Health Perspect 2008, 116:734-739.

8. Leaf A: Omega-3 fatty acids and prevention of arrhythmias. Curr Opin Lipidol 2007, 18:31-34.

9. Tziomalos K, Athyros VG, Mikhailidis DP: Fish oils and vascular disease prevention: an update. Curr Med Chem 2007, 14:2622-2628.

10. Ballatori N, Clarkson TW: Biliary secretion of glutathione and of glutathione-metal complexes. Fundam Appl Toxicol 1985, 5:816-831.

11. Dutczak WJ, Ballatori N: Transport of the glutathione-methylmercury complex across liver canalicular membranes on reduced glutathione carriers. J Biol Chem 1994, 269:9746-9751.

12. NCBI Unigene Database. [http://www.ncbi.nlm.nih.gov/entrez/query.fcgi? $\mathrm{db}=$ unigene].

13. Hayes JD, Strange RC: Glutathione S-transferase polymorphisms and their biological consequences. Pharmacology 2000, 61:154-166.

14. Strange RC, Fryer AA: The glutathione S-transferases: influence of polymorphism on cancer susceptibility. IARC SCi Publ 1999, 231-249.

15. Koide S, Kugiyama K, Sugiyama S, Nakamura S, Fukushima H, Honda O, Yoshimura M, Ogawa H: Association of polymorphism in glutamatecysteine ligase catalytic subunit gene with coronary vasomotor dysfunction and myocardial infarction. J Am Coll Cardiol 2003, 41:539-545.

16. Nakamura S, Kugiyama K, Sugiyama S, Miyamoto S, Koide S, Fukushima H, Honda O, Yoshimura M, Ogawa H: Polymorphism in the 5'-flanking region of human glutamate-cysteine ligase modifier subunit gene is associated with myocardial infarction. Circulation 2002, 105:2968-2973.

17. Nakamura S, Sugiyama S, Fujioka D, Kawabata K, Ogawa H, Kugiyama K: Polymorphism in glutamate-cysteine ligase modifier subunit gene is associated with impairment of nitric oxide-mediated coronary vasomotor function. Circulation 2003, 108:1425-1427.

18. Ali-Osman F, Akande O, Antoun G, Mao JX, Buolamwini J: Molecular cloning, characterization, and expression in Escherichia coli of full-length CDNAs of three human glutathione S-transferase Pi gene variants. Evidence for differential catalytic activity of the encoded proteins. J Biol Chem 1997, 272:10004-10012.

19. Sundberg K, Johansson AS, Stenberg G, Widersten M, Seidel A, Mannervik B, Jernstrom B: Differences in the catalytic efficiencies of allelic variants of glutathione transferase P1-1 towards carcinogenic diol epoxides of polycyclic aromatic hydrocarbons. Carcinogenesis 1998, 19:433-436.

20. Zimniak P, Nanduri B, Pikula S, Bandorowicz-Pikula J, Singhal SS, Srivastava SK, Awasthi S, Awasthi YC: Naturally occurring human glutathione S-transferase GSTP1-1 isoforms with isoleucine and valine in position 104 differ in enzymic properties. Eur J Biochem 1994, 224:893-899.

21. Custodio HM, Harari R, Gerhardsson L, Skerfving S, Broberg K: Genetic influences on the retention of inorganic mercury. Arch Environ Occup Health 2005, 60:17-23.

22. Gundacker C, Wittmann KJ, Kukuckova M, Komarnicki G, Hikkel I, Gencik M: Genetic background of lead and mercury metabolism in a group of medical students in Austria. Environ Res 2009, 109:786-796.

23. Sandborgh-Englund G, Elinder CG, Langworth S, Schutz A, Ekstrand J: Mercury in biological fluids after amalgam removal. J Dent Res 1998, 77:615-624.

24. Boberg M, Croon LB, Gustafsson IB, Vessby B: Platelet fatty acid composition in relation to fatty acid composition in plasma and to serum lipoprotein lipids in healthy subjects with special reference to the linoleic acid pathway. Clin Sci (Lond) 1985, 68:581-587.

25. Svensson BG, Akesson B, Nilsson A, Skerfving S: Fatty acid composition of serum phosphatidylcholine in healthy subjects consuming varying amounts of fish. Eur J Clin Nutr 1993, 47:132-140.

26. NCBI SNP Database. [http://www.ncbi.nlm.nih.gov/SNP].

27. Tosic M, Ott J, Barral S, Bovet P, Deppen P, Gheorghita F, Matthey ML, Parnas J, Preisig M, Saraga M, Solida A, Timm S, Wang AG, Werge T,
Cuénod M, Do KQ: Schizophrenia and oxidative stress: glutamate cysteine ligase modifier as a susceptibility gene. Am J Hum Genet 2006, 79:586-592.

28. Jonsson LS, Broberg $K$, Bergendorf $U$, Axmon A, Littorin M, Jonsson BA: Levels of 2-thiothiazolidine-4-carboxylic acid (TTCA) and effect modification of polymorphisms of glutathione-related genes in vulcanization workers in the southern Sweden rubber industries. Int Arch Occup Environ Health 2007, 80:589-598.

29. Carvalho CM, Chew EH, Hashemy SI, Lu J, Holmgren A: Inhibition of the human thioredoxin system. A molecular mechanism of mercury toxicity. J Biol Chem 2008, 283:11913-11923.

doi:10.1186/1476-069X-10-33

Cite this article as: Engström et al:: Evaluation of the impact of genetic polymorphisms in glutathione-related genes on the association between methylmercury or $n-3$ polyunsaturated long chain fatty acids and risk of myocardial infarction: a case-control study. Environmental Health 2011 10:33.

\section{Submit your next manuscript to BioMed Central and take full advantage of:}

- Convenient online submission

- Thorough peer review

- No space constraints or color figure charges

- Immediate publication on acceptance

- Inclusion in PubMed, CAS, Scopus and Google Scholar

- Research which is freely available for redistribution

Submit your manuscript at www.biomedcentral.com/submit
Ciomed Central 